\title{
Serodiagnosis of Helicobacter pylori infection by Cobas Core ELISA in adults from Minas Gerais, Brazil
}

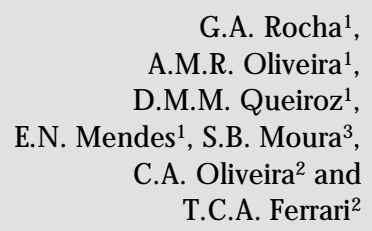

G.A. Rochaㄹ, A.M.R. Oliveira ${ }^{1}$, D.M.M. Q ueiroz ${ }^{1}$ E.N. Mendes ${ }^{1}$, S.B. Moura ${ }^{3}$, C.A. Oliveira ${ }^{2}$ and T.C.A. Ferrari²

\author{
${ }^{1}$ Laboratório de Pesquisa em Bacteriologia and \\ ${ }^{2}$ Departamento de Clínica Médica, Faculdade de Medicina, and \\ ${ }^{3}$ Departamento de Microbiologia, Instituto de Ciências Biológicas, \\ Universidade Federal de M inas Gerais, Belo Horizonte, M G, Brasil
}

\section{Correspondence \\ D.M.M. Q ueiroz \\ Laboratório de Pesquisa em \\ Bacteriologia, FM, UFM G \\ Av. Alfredo Balena, 190, S. 4026 \\ 30130-100 Belo Horizonte, M G Brasil \\ Fax: +55-31-274-2767 \\ E-mail: dqueiroz@ medicina.ufmg.br \\ Research supported by CNPq, FAPEMIG, PRPq/UFMG and FINEP.}

Received January 8, 1998 Accepted August 3, 1998

\section{Abstract}

We evaluated the accuracy of a 2nd generation ELISA to detect Helicobacter pylori infection in adults from a developing country in view of variations in sensitivity and specificity reported for different populations. We studied 97 non-consecutive patients who underwent endoscopy for evaluation of dispeptic symptoms. The presence of $H$. pylori was determined in antral biopsy specimens by culture, by the preformed urease test and in carbolfuchsin-stained smears. Patients were considered to be $H$. pylori positive if at least two of the three tests presented a positive result or if the culture was positive, and negative if the three tests were negative. Sixty-five adults ( 31 with peptic ulcer) were $H$. pylori positive and 32 adults were $H$. pylori negative. Antibodies were detected by Cobas Core anti-H. pylori EIA in 62 of $65 \mathrm{H}$. pylori-positive adults and in none of the negative adults. The sensitivity, specificity and positive and negative predictive values of the test were 95.4, 100, 100 and 91.4\%, respectively. The Cobas Core anti- $H$. pylori EIA presented high sensitivity and specificity when employed for a population in Brazil, permitting the use of the test both to confirm the clinical diagnosis and to perform epidemiologic surveys.

\section{Introduction}

Helicobacter pylori is now recognized as the major etiologic agent of gastritis, as an essential factor in the pathogenesis of peptic ulcer (1) and also as a factor involved in the etiopathogenesis of gastric carcinoma $(2,3)$.

Several methods have been employed for the diagnosis of $H$. pylori infection. Methods such as culture (4), determination of the presence of the microorganism in stained smears (5) and in histological sections (6),

\section{Key words}

- Helicobacter pylori

- Serodiagnosis

- ELISA

\section{- ELISA}


ity of the ELISA depend on the antigen preparation employed $(14,15)$ and the gold standard used to compare tests $(16,17)$. Tests that employ partially or highly purified antigens free of flagellar proteins (considered as 2nd generation) have improved the accuracy of ELISA $(14,18)$. With respect to the gold standard, the use of 2 or more tests has been recommended for the diagnosis of infection. Also, it is recommended that a result should be considered truly positive only when at least 2 tests are positive, and truly negative when all the tests are negative. The result should also be considered truly positive when only the culture is positive because, in this case, no false-positive results are expected (17).

In addition to these considerations the literature has reported variations in the sensitivity and specificity of serologic tests when different populations are studied. Goossens et al. (12), using the same commercial ELISA kit in populations of different origins, demonstrated high specificity (95\%) of the test for the population of Belgium and only $70 \%$ specificity for the population of Mediterranean origin. For these reasons, it is highly advisable to evaluate an ELISA on the population to be studied by testing a well-defined serum panel before its use as a diagnostic tool for $H$. pylori $(12,16,19)$.

Therefore, the present study was designed to evaluate the accuracy of a 2 nd generation ELISA to detect $H$. pylori infection in adults from Minas Gerais, Brazil, employing 3 methods (culture, urease test and stained smears) as the gold standard and adopting

Table 1 - Characteristics of the population studied.

\begin{tabular}{lcccc}
\hline Patients & Number & $\begin{array}{c}\text { Male/female } \\
\text { ratio }\end{array}$ & $\begin{array}{c}\text { Mean age } \pm \text { SD } \\
\text { (years) }\end{array}$ & $\begin{array}{c}\text { Range } \\
\text { (years) }\end{array}$ \\
\hline H. pylori positive & 65 & $30 / 35$ & $42.0 \pm 13.4$ & $20-78$ \\
Duodenal ulcer & 31 & $13 / 18$ & $42.5 \pm 11.9$ & $24-76$ \\
Gastritis & 34 & $17 / 17$ & $41.5 \pm 14.7$ & $20-78$ \\
H. pylori negative & 32 & $14 / 18$ & $43.8 \pm 15.6$ & $21-76$ \\
Total & 97 & $44 / 53$ & $42.5 \pm 14.1$ & $20-78$ \\
& & & &
\end{tabular}

specific and rigorous criteria to establish the diagnosis of infection.

\section{Patients and Methods}

This project was approved by the Ethics Committee of Hospital das Clínicas, Universidade Federal de Minas Gerais, Brazil, and informed consent was obtained from all patients.

From January to December 1995 we studied prospectively 97 non-consecutive patients (44 men and 53 women; mean age, 42.5 years; range, 20 to 78 years) who underwent upper gastrointestinal endoscopy for evaluation of symptoms related to the upper gastrointestinal tract. Patients taking antimicrobial drugs during the last 3 months before endoscopy were not included in the study. Among the H. pylori-positive patients 31 (13 males and 18 females) presented peptic ulcer. The characteristics of the studied population are listed in Table 1.

At endoscopy, 3 biopsy specimens were obtained from the antral gastric mucosa for H. pylori identification. One fragment was placed in a tube containing Christensen's $2 \%$ urea agar. Another specimen was smeared on a glass slide, heat fixed, stained with $40 \%$ carbolfuchsin (20) and examined under an immersion lens. The specimen for culture was kept in thioglycolate broth (Difco Laboratories, Detroit, $\mathrm{MI})$ at $4^{\circ} \mathrm{C}$ for no longer than $5 \mathrm{~h}$ before processing. The tissue specimens were homogenized in tissue grinders and plated onto Belo Horizonte medium (BHM) (4). The plates were incubated at $37^{\circ} \mathrm{C}$ in a microaerophilic environment for up to 7 days. Colonies of $H$. pylori were identified by Gram-negative appearance, positive oxidase and catalase tests, and a rapidly positive urease test.

Patients were considered to be $H$. pylori positive if at least two of the three tests were positive or if the culture alone was positive, and negative, if the three tests were negative.

Blood samples were drawn from each 
patient for serology at the time of endoscopy and the sera were stored at $-20^{\circ} \mathrm{C}$ before testing.

H. pylori antibodies were assayed by the Cobas Core anti-H. pylori IgG EIA (Roche Diagnostic Systems, Basel, Switzerland), a second generation EIA that employs a wellcharacterized and highly immunogenic purified $H$. pylori-specific multi-component antigen preparation containing urease and free of cross-reacting flagellar proteins $(18,21)$. The test was performed according to manufacturer's instructions. Briefly, patient and control samples were diluted and allowed to react for $15 \mathrm{~min}$ at $37^{\circ} \mathrm{C}$ with $H$. pylori antigen-coated beads. After a washing step, the peroxidase-conjugated goat anti-human IgG antibody was added and incubated for $15 \mathrm{~min}$ at $37^{\circ} \mathrm{C}$. After removal of the unbound conjugate by a washing step, the beads were incubated with a substrate solution containing tetramethylbenzidine and hydrogen peroxide. The enzymatic reaction was stopped by the addition of acid, and absorbance at $450 \mathrm{~nm}$ was determined. The concentrations of IgG antibody in the serum samples were determined by interpolation from a standard curve constructed by dilution of the positive control and by plotting absorbance values obtained for each standard against the corresponding anti-H. $p y$ lori concentrations (in $\mathrm{U} / \mathrm{ml}$ ). The values within $\pm 10 \%$ of the cutoff were considered to be equivocal.

The performance of the test was evaluated by determining the sensitivity, specificity and positive and negative predictive values with a 95\% confidence interval (CI).

The interassay reproducibility of the test was evaluated by testing 20 positive serum samples (10 from patients with duodenal ulcer and 10 from patients with gastritis) and 10 negative serum samples (selected at random) on different days and the intra-assay reproducibility by testing twice the same sera on the same day.

The $\chi^{2}$ test was used to compare propor- tions between groups (sex distribution and sensitivity). Analysis of variance for variables of normal distribution and the KruskalWallis test for variables of asymmetrical distribution were employed to evaluate differences in IgG concentration and differences in age among groups. Spearman's correlation was used to compare IgG concentration and patient age. The level of significance was set at $\mathrm{P}<0.05$.

\section{Results}

H. pylori was identified by microbiological methods in 65 of the 97 (67.0\%) patients studied. The $H$. pylori-positive (with and without peptic ulcer) and -negative groups were similar with respect to age $(\mathrm{P}=0.81)$ and gender $(\mathrm{P}=0.78)$.

Anti-H. pylori antibodies were detected in 62 of $65(95.4 \%) H$. pylori-positive subjects and in none of the negative ones (Table 2). There were no equivocal results. Among the 3 patients who were $H$. pylori-positive by microbiological methods but who were negative by serology, 2 had gastritis alone and 1 had peptic ulcer. The sensitivity, specificity and positive and negative predictive values of ELISA, with their 95\% CI, for adults were 95.4\% (88.5-98.4\%), 100\% (96.4-100\%), $100 \%$ (96.4-100\%) and 91.4\% (83.5-95.9\%), respectively (Table 2). There was no significant difference in sensitivity between patients with (96.7\%) and without peptic ulcer

Table 2 - Sensitivity, specificity, and predictive values of Cobas Core ELISA in 97 patients undergoing endoscopy.

Sens., Sensitivity; Spec., specificity; PPV, positive predictive value; NPV, negative predictive value.

\begin{tabular}{|c|c|c|c|c|c|c|}
\hline \multirow{2}{*}{$\begin{array}{l}\text { Cobas Core } \\
\text { ELISA }\end{array}$} & \multicolumn{2}{|c|}{ Patients } & \multicolumn{4}{|c|}{ ELISA results } \\
\hline & $\begin{array}{l}\text { with } \mathrm{H} \text {. pylori } \\
\qquad(\mathrm{N}=65)\end{array}$ & $\begin{array}{l}\text { without } \mathrm{H} \text {. pylori } \\
\qquad(\mathrm{N}=32)\end{array}$ & Sens. & Spec. & PPV & NPV \\
\hline Positive & 62 & 0 & & & & \\
\hline Negative & 3 & 32 & $95.4 \%$ & $100 \%$ & $100 \%$ & $91.4 \%$ \\
\hline
\end{tabular}


(94.1\%) $(\mathrm{P}=1.0)$. No significant differences $(\mathrm{P}=0.71)$ in $\mathrm{IgG}$ concentration were observed in these groups (median $=56.2 \mathrm{U} / \mathrm{ml}$, range 5.0 to $597.9 \mathrm{U} / \mathrm{ml}$ for patients with peptic ulcer, and median $=37.1 \mathrm{U} / \mathrm{ml}$, range 2.1 to $1041.2 \mathrm{U} / \mathrm{ml}$ for patients without peptic ulcer).

In regard to inter- and intra-assay reproducibility, 29 of 30 serum samples showed identical qualitative results on repeated testing on different days and on the same day.

There was no significant difference in IgG concentration between the sera from males (mean $=98.5 \mathrm{U} / \mathrm{ml}, \mathrm{SD}=120.0)$ and females $($ mean $=120.9 \mathrm{U} / \mathrm{ml}, \mathrm{SD}=169.8)$ with peptic ulcer $(\mathrm{P}=0.68)$. In contrast, the IgG concentration in the sera from females with gastritis $($ median $=53.3 \mathrm{U} / \mathrm{ml}$, range 15.8 to $1041.2 \mathrm{U} / \mathrm{ml}$ ) was significantly higher than in males with gastritis (median $14.2 \mathrm{U} /$ $\mathrm{ml}$, range 2.1 to $436.4 \mathrm{U} / \mathrm{ml})(\mathrm{P}=0.008)$. No differences in $\mathrm{IgG}$ concentration were observed among adults of different ages $(\mathrm{P}=$ 0.12 ).

\section{Discussion}

Several ELISA tests are commercially available to diagnose $H$. pylori infection in adults. Their sensitivity and specificity depend on the gold standards used to compare the tests, the nature of the antigens employed and the value chosen for the cutoff. Employing 3 methods as gold standard - culture on BHM whose sensitivity is comparable to that of PCR (21), carbolfuchsin-stained smears and preformed urease test - and considering $H$. pylori positivity to be present when at least 2 tests were positive or if the culture was positive, and $H$. pylori negativity to be present when all 3 tests were negative, we observed high sensitivity (95.4\%) and specificity $(100 \%)$ of Cobas Core for the diagnosis of $H$. pylori infection in adults.

As reported by others $(12,15)$, the results of the present study demonstrated that the intra- and the interassay reproducibility of this ELISA was excellent.

Although the number of patients in this study was not very large, the size of the sample was sufficient, as demonstrated by the less than $10 \%$ amplitude of the $95 \% \mathrm{CI}$ for all indicators of the test.

Thus, the high sensitivity (95\%) observed permits the safe use of the test in epidemiologic surveys. However, this value is not sufficiently high to exclude the diagnosis of infection in the presence of a negative test at the individual level, although the probability of the existence of disease in this situation is low. On the other hand, the $100 \%$ specificity we observed permits us to confirm the diagnosis of infection when the result is positive.

Employing the same ELISA kit and considering a truly positive result when culture and/or histology was positive, a similar result was demonstrated by Goossens et al. (12) for Belgian patients (93 and 96\% sensitivity and 95 and $91 \%$ specificity for adults 18-40 years old and $>40$ years old, respectively). Debongnie et al. (22), also in Belgium, using culture, and Trautmann et al. (18) in Germany, using bacterial detection in histological sections, culture, urease test and Western blot as gold standard (with the patient considered to be positive when one of the tests was positive), demonstrated 98.6 and $96 \%$ sensitivity and 94.4 and $97 \%$ specificity for the Cobas Core, respectively.

An explanation for this high sensitivity and specificity of the Cobas Core is the use of second-generation antigens consisting of highly immunogenic purified $H$. pylori proteins, including urease, a fact that increases sensitivity, and free of flagellar proteins, a fact that prevents cross-reaction with microorganisms of the genus Campylobacter and, therefore, increases specificity $(18,23)$. In this study we observed high specificity, as also observed by several investigators in developed countries. In the present study anti-H. pylori antibodies were not detected in any of the non-infected patients (100\% specificity). Probably the three methods of 
diagnosing infection used and the rigid criteria for establishing negativity contributed to the fact that no patient was erroneously classified as $H$. pylori negative. However, in some populations the specificity of the test is very low as observed by Goossens et al. (12) for Mediterranean patients and by Antoine et al. (13) for the French patients, indicating that the ELISA must be validated for different populations.

The serologic test was negative in three patients found to be $H$. pylori positive by microbiological methods (two with gastritis and one with duodenal ulcer). Similar falsenegatives have been reported by several investigators $(12,13)$. The most likely explanation is that in some patients no systemic IgG antibodies will occur although $H$. pylori can be detected from the gastric biopsy specimens, i.e., they failed to seroconvert. Another explanation is that, although the kit employed contained several antigenic components including urease, which is highly immunogenic, some patients may harbor bacterial strains with few antigenic determinants in common with the strains used to obtain the antigen. In this case, the use of another ELISA employing a different antigen or of another method for antibody detection such as immunoblotting may demon- strate the presence of anti- $H$. pylori $\mathrm{IgG}$. Furthermore, since in Brazil the infection occurs at an early age, the patients with gastritis may develop atrophy of the gastric mucosa with a consequent decrease in number of bacteria, a fact that may alter the production of antibodies. However, histological examination of the false-negative cases observed here did not reveal atrophy but only the presence of chronic gastritis of moderate intensity.

As reported by others $(23,24)$, in the present study we also observed that $\mathrm{IgG}$ concentration in adults does not permit the discrimination between gastritis and duodenal ulcer. We have no explanation for the observation that the $\mathrm{IgG}$ concentration in the sera from females with gastritis was significantly higher than in males with gastritis.

In conclusion, the ELISA for $H$. pylori diagnosis presented high sensitivity and specificity when employed for a population in one state in Brazil, permitting the use of the test both to confirm the clinical diagnosis and to perform epidemiologic surveys. However, in order to rule out $H$. pylori infection with safety in the presence of a negative test, the use of a more sensitive method or of a combination of methods becomes necessary for clinical diagnosis.

\section{References}

1. Mégraud F \& Lamouliatte H (1992). Helicobacter pylori and duodenal ulcer. Digestive Diseases and Sciences, 37: 769-772.

2. Parsonnet J, Friedman GD, Vandersteen DP, Chang Y, Vogelman J H, Orentreich $\mathrm{N}$ \& Sibley RK (1991). Helicobacter pylori infection and the risk of gastric carcinoma. New England J ournal of Medicine, 325: 1127-1131.

3. Blaser MJ \& Parsonnet J (1994). Parasitism by the "slow" bacterium Helicobacter pylori leads to altered gastric homeostasis and neoplasia. J ournal of Clinical Investigation, 94: 4-8.

4. Queiroz DMM, Mendes EN \& Rocha GA (1987). Indicator medium for isolation of Campylobacter pylori. J ournal of Clinical
Microbiology, 25: 2378-2379.

5. J ones DM, Lessels AM \& Eldridge J (1984). Campylobacter-like organisms on the gastric mucosa: culture, histological and serological studies. J oumal of Clinical Pathology, 37: 1002-1006.

6. Gray SF, Wyatt J \& Rathbone BJ (1986). Simplified techniques for identifying $C$. pylori. J oumal of Clinical Pathology, 39: 1279-1280.

7. Marshall BJ, Warren J R, Francis GJ , Langton SR, Goodwin CS \& Blicow ED (1987). Rapid urease test in the management of Campylobacter pyloridis-associated gastritis. American J ournal of Gastroenterology, 82: 200-210.

8. Hammar M, Tyszkiewicz T, Wadstrom T
\& O'Toole PW (1992). Rapid detection of Helicobacter pylori in gastric biopsy material by polymerase chain reaction. J ournal of Clinical Microbiology, 30: 54-58.

9. Mitchell HM, Lee A, Berkowickz J \& Borody T (1988). The use of serology to diagnose active Campylobacter pylori infection. Medical J ournal of Australia, 149: 604-609.

10. Andersen LP (1993). The antibody response to Helicobacter pylori infection and the value of serological tests to detect $\mathrm{H}$. pylori and for post-treatment monitoring. In: Goodwin CS \& Worsley BW (Editors), Helicobacter pylori: Biology and Clinical Practice. CRC Press, Boca Raton.

11. Graham DY, Klein PD, Evans DJ , Opekun 
AR \& Boutton TW (1987). Campylobacter pylori detected non invasively by the carbon ${ }^{13}$-urea breath test. Lancet, 1: 11741177.

12. Goossens $H$, Glupczynski $Y$, Burette $A$, van den Borre C \& Butzler JP (1992). Evaluation of a commercially available second-generation immunoglobulin $\mathrm{G}$ enzyme immunoassay for detection of Helicobacter pylori infection. J ournal of Clinical Microbiology, 30: 176-180.

13. Antoine C, Lozniewski A, De Korwin J D, Conroy MC, Feldmann L, Duprez A \& Weber M (1995). Étude comparative de quatre méthodes sérologiques commercialisées pour le diagnostic de l'infection gastrique à Helicobacter pylori. Gastroentérologie Clinique et Biologique, 19: 182188.

14. Hirschl AM, Rathbone BJ, Wyatt JI, Berger J \& Rotter ML (1990). Comparison of ELISA antigen preparations alone or in combination for serodiagnosing Helicobacter pylori infections. J ournal of Clinical Pathology, 43: 511-513.

15. Lelwala-Guruge J, Nilsson I, Ljungh A \& Wadstrom T (1992). Cell surface proteins of Helicobacter pylori as antigens in an ELISA and a comparison with three commercial ELISA. Scandinavian J ournal of
Infectious Diseases, 24: 457-465.

16. Fauchère $J \mathrm{~L}$ (1996). Evaluation of the antiHelicobacter pylori serum antibody response. In: Lee A \& Mégraud F (Editors), Helicobacter pylori: Techniques for Clinical Diagnosis and Basic Research. W.B. Saunders Company Ltd., London.

17. Mégraud F (1996). Advantages and disadvantages of current diagnostic tests for the detection of Helicobacter pylori. Scandinavian J ournal of Gastroenterology, 215: 57-62.

18. Trautmann M, Moldrzyk M, Vogt K, Korber J, Held T \& Marre R (1994). Use of a receiver operating characteristics in the evaluation of two commercial enzyme immunoassays for detection of Helicobacter pylori infection. European J ournal of Clinical Microbiology and Infectious Diseases, 13: 812-819.

19. J ensen AKV, Andersen LP \& Wachmann $\mathrm{CH}$ (1993). Evaluation of eight commercial kits for Helicobacter pylori IgG antibody detection. Acta Pathologica Microbiologica et Immunologica Scandinavica, 101: 795-801.

20. Queiroz DMM, Rocha GA, Mendes EN, Lage AP, Carvalho ACT \& Barbosa AJ A (1990). A spiral microorganism in the stomach of pigs. Veterinary Microbiology,
24: 199-204.

21. van Zwet AA, Thijs JC, Kooistra-Smid AMD, Schirm J \& Snijder J AM (1993). Sensitivity of culture compared with that of polymerase chain reaction for detection of Helicobacter pylori from antral biopsy samples. J ournal of Clinical Microbiology, 31: 1918-1920.

22. Debongnie J C, Durez $P \&$ Luyasu $V$ (1993). Validation et usage clinique et épidémiologique d'un test sérologique commercialisé dans le diagnostic de l'infection à Helicobacter pylori. Gastroentérologie Clinique et Biologique, 17: 98102.

23. Andersen LF \& Gaarslev K (1992). IgG subclass antibodies against Helicobacter pylori heat-stabile antigens in normal persons and in dyspeptic patients. Acta Pathologica Microbiologica et Immunologica Scandinavica, 100: 747-751.

24. Bontkes HJ, Veenendaal RA, Peña AS, Goerhard J G, van Duijn W, Kuiper I, Meijer J L \& Lamers CBHW (1992). IgG subclass response to Helicobacter pylori in patients with chronic active gastritis and duodenal ulcer. Scandinavian J ournal of Gastroenterology, 27: 129-133. 